\title{
The effect of refined nursing applied in the nursing room of thoracoscopic lung cancer radical operation in Southwestern China
}

\author{
Caihong $\mathrm{HU}^{1}$, Changming $\mathrm{ZHAO}^{1}$, Ping $\mathrm{LAI}^{1}$, Xiaofang WANG ${ }^{1}$, Zhengbo LIANG ${ }^{1 \star}$ (ic
}

\begin{abstract}
The purpose of this study is to apply refined nursing in the operation room of thoracoscopic lung cancer radical surgery in southwestern China ${ }^{* *}$ hospital through refined nursing. Patients in the control group were given routine nursing care, and patients in the experimental group were given refined nursing care. The intraoperative blood loss, extubation time, length of stay, and total nursing satisfaction rate were compared between the two groups of patients The intraoperative blood loss of the patients in the experimental group was $192.94 \pm 3.63 \mathrm{~mL}$, and the hospital stay was $10.08 \pm 1.64$ days, which were lower than those in the control group $(221.46 \pm 4.31 \mathrm{~mL}$ and $16.62 \pm 1.83$ days, respectively), and the difference was statistically significant $(P<0.05)$. There was no significant difference in extubation time between the experimental group and the control group $(P>0.05)$. The complications in the experimental group were lower than those in the control group, and the overall nursing satisfaction rate was higher in the experimental group than in the control group. The differences between the two groups were statistically significant $(P<0.05)$. Refined nursing applied to the operation room of thoracoscopic lung cancer radical surgery surgery can reduce the intraoperative bleeding volume and complications of patients, shorten the length of hospitalization of patients, improve the patient's nursing satisfaction, and is worthy of clinical application.
\end{abstract}

Keywords: refined nursing; thoracoscopy radical lung cancer surgery; operating room nursing.

Practical Application: Refined nursing applied to the operation room of thoracoscopic lung cancer radical surgery surgery improves patient's nursing satisfaction, and is worthy of clinical application.

\section{Introduction}

Lung cancer is a malignant tumor with a high incidence worldwide, about $31 \%$ of cancer-related deaths are caused by lung cancer, which has a poor prognosis and a high mortality rate (Alghamdi et al., 2018; Bertaglia et al., 2017; Kenamond et al., 2018). In recent years, with the development of the economy, China has become one of the countries with the fastest increasing incidence of lung cancer, and the age of onset has also become younger (Deng et al., 2020). Local symptoms of lung cancer are caused by the tumor itself irritating, blocking, infiltrating, and compressing the tissue when it grows locally (Clarke et al., 2019; Samson et al., 2019). About 600,000 people die each year in China, which seriously threatens people's physical and mental health and quality of life (Tian et al., 2020; Wang et al., 2017).

According to the type of pathology, lung cancer can be divided into small cell lung cancer and non-small cell lung cancer (Calado et al., 2017; Filippou et al., 2019; Hasan et al., 2019). The pathogenesis is not very clear, it may be caused by smoking, long-term exposure to air pollution, and exposure to carcinogens in occupations (Chin et al., 2017). At present, the effective method for clinical treatment of lung cancer is radical tumor surgery (Reymen et al., 2020). Especially in recent years, the development of minimally invasive surgery has made thoracoscopic tumor resection to gradually replace the traditional thoracotomy, mainly due to the small surgical trauma, rapid postoperative recovery and high safety (Shirai et al., 2019). Most patients with non-small cell lung cancer have no typical early manifestations (Miao et al., 2019). Only a small number of patients may have symptoms such as cough, sputum, and blood in the sputum, which results in a lower diagnosis rate (Xie et al., 2017). At present, the clinical treatment of lung cancer is mostly surgery. Among them, thoracoscopy radical lung cancer surgery is the most commonly used. It has the advantages of minimally invasive, less bleeding, mild pain, and rapid postoperative recovery, and has been recognized by patients.

It is worth noting that in addition to the clinical experience of the physician, the precision of the surgical instruments, and other factors, the quality of the operating room's level of refined nursing also affects the treatment effect and clinical prognosis (Levy-Storms et al., 2005). This study evaluated the effectiveness of refined nursing with thoracoscopic surgery for the treatment of lung cancer under thoracoscopic surgery in the Southwestern China ${ }^{* * *}$ Hospital.

\section{Materials and methods}

\subsection{General demographic information}

130 patients with lung cancer who underwent thoracoscopic lung cancer radical surgery in Southwest China ${ }^{* *}$ Hospital 
during January to December 2019 were selected as the subjects of this study. All patients included in the study were divided into control group and experimental group according to the random number table method, with 65 cases in each group.

\subsection{Research method}

The control group carried out routine nursing. The specific contents included assisting doctors in preparing the relevant surgical equipment, closely observing the patient's vital signs during the operation, and following the doctor's instructions on the medication and dietary care.

The experimental group implements refined nursing, and the specific steps include the following. Preoperative care, the nursing staff must comprehensively evaluate the actual situation of the patient, understand whether the patient has a history of allergies and other medical history. Communicate with patients and popularize their knowledge about thoracoscopic surgery. Observe the patient's emotional changes and give positive encouragement to patients with severe fear. You can communicate the successful case with the patient. Intraoperative nursing, communicating with the doctor, assisting the doctor in performing the operation, assisting the doctor in tracheal intubation, and closely observing the patient's blood pressure, heart rate and other vital signs during the operation. Keep the ward clean and tidy after operation and maintain proper temperature. After the operation, the blood stains are carefully wiped and the patient is dressed properly. During the transfer process, the chest tube needs to be closed and the chest tube folded and twisted. Patients will experience pain after surgery, so the nursing staff must be patient to explain the causes of postoperative pain to the family members, including surgical complications, so that patients and family members can understand, eliminate unnecessary concerns, and put in place various preventive measures. Caregivers need to keep patients calm and reduce agitation. Continuous ECG monitoring and close monitoring of patients' vital signs and arrhythmias. Strictly control the speed and volume of infusion to prevent the infusion from going too fast. The speed should not exceed 20 to 30 drops $/ \mathrm{min}$. The diet starts with the simplest liquid, and if there are no adverse reactions in the gastrointestinal tract, then transition to semi-liquid and general food. The patients were revisited within 3 days after the operation to observe the wounds of the patients. If redness appeared, they should be treated in time. One week after the operation, the patients were instructed to get out of bed for proper exercise, and the nursing staff could accompany them for jogging, walking, and activities. However, it is necessary to pay attention to patients' inability to move too much so as not to damage their bodies and cause damage to the health status of patients with lung cancer.

\subsection{Evaluation standard}

The intraoperative blood loss, extubation time, and hospital stay were compared between the two groups of patients. The total nursing satisfaction rate was compared between the two groups. It was carried out through a self-made questionnaire questionnaire in our hospital, and the self-made nursing satisfaction questionnaire was used for evaluation. It was divided into unsatisfactory, average, and satisfactory according to the patient satisfaction level. Patients were graded according to their level of satisfaction, and the researchers conducted statistical analysis of the count data on the questionnaire. The overall number of satisfied patients $=$ very satisfied + general satisfied .

\subsection{Statistical methods}

The research data were entered through the Epidata database and analyzed and compared using SPSS 23.0 software. Quantitative data are described in the form of (mean \pm standard deviation) and $\mathrm{t}$-tested. Count data are expressed as $\mathrm{n}(\%)$ and subjected to chi-square analysis or rank sum test. $\mathrm{P}<0.05$ considered the difference to be statistically significant.

\section{Results}

\subsection{Comparison of general characteristics between test group and control group}

Among the patients in the test group, 35 were male and 30 were female, the age range of patients was between 28-77 years, with an average age of $(56.1 \pm 7.8)$ years. Among the patients in the control group, 34 were male and 31 were female, the age range of patients was between $27-75$ years, and the average age was $(55.3 \pm 7.2)$ years. There were no significant differences in gender and age between the experimental group and the control group $(P>0.05)$.

\subsection{Comparison of intraoperative blood loss, extubation time, and hospital stay between the two groups of patients}

The intraoperative blood loss of patients in the test group was $192.94 \pm 3.63 \mathrm{~mL}$, and the length of hospital stay was $10.08 \pm 1.64$ days, which were lower than those in the control group (221.46 $\pm 4.31 \mathrm{~mL}$ and $16.62 \pm 1.83$ days, respectively), the difference was statistically significant $(\mathrm{P}<0.05)$. There was no significant difference in extubation time between the experimental group and the control group $(3.72 \pm 0.48 \mathrm{~d}$ and $3.90 \pm 0.67 \mathrm{~d}$, respectively) $(\mathrm{P}>0.05)$. The statistical analysis result is shown in Table 1 .

\subsection{Comparison of the incidence of complications between the two groups of patients}

The complications in the test group were 1 case of pleural effusion, 2 cases of incision infection, 1 case of anastomotic bleeding, and the incidence of complications was $6.15 \%$ (4/65). The complications in the control group were pleural effusion in 2 cases, incision infection in 6 cases, and anastomotic bleeding in 4 cases. The incidence of complications was $18.46 \%(12 / 65)$. The difference between the two groups was statistically significant $(P<0.05)$. The statistical analysis results is shown in Table 2 .

\subsection{Comparison of overall nursing satisfaction between the experimental group and the control group}

The overall nursing satisfaction rate of the test group was $93.85 \%$ (61/65), which was higher than the control group of $81.54 \%(53 / 65)$. The difference between the two groups was 
statistically significant $(P<0.05)$. The statistical analysis table is shown in Table 3.

\section{Discussion}

Lung cancer is one of the leading causes of cancer-related deaths worldwide (Yoo et al., 2019; Yu et al., 2018), according to statistics released by the Cancer Center of China, there are 4.3 million new cases of cancer in China each year (Wang et al., 2019; Zhang et al., 2018; Jiang et al., 2019). Among them, lung cancer occupies the top spot due to its high morbidity and mortality. It is estimated that by 2025 , there will be 1 million lung cancer patients in China (Sun et al., 2020; Feng et al., 2020; Xing et al., 2019). Therefore, lung cancer has replaced cardiovascular disease as the biggest factor threatening the safety of national survival. At present, the main clinical treatment of lung cancer is thoracoscopy radical surgery for lung cancer (Venkitaraman et al., 2019). When found early, surgical resection has a good prognosis, and the 5-year survival rate for small localized stage I tumors is $70 \%$.

For patients with early lung cancer, early surgical treatment can help to achieve the desired prognosis (Glatzer et al., 2017). However, the occurrence of postoperative oxidative stress lung injury and other complications will not only affect the improvement of patients' lung function, but also reduce the quality of life of patients. The care of patients after lung cancer surgery is a key, it is related to the patient's postoperative recovery. This study was compared through the intervention of conventional nursing and refined nursing. Through analysis, fine-grained nursing is more targeted and comprehensively carried out from the perspective of the patient. The results of this study suggest that the clinical effect of the observation group of refined nursing is better and the nursing satisfaction is higher.

Non-small cell lung cancer has the characteristics of high incidence, slow division of cancer cells, long metastasis and spreading time (Bacha et al., 2017; Chen et al., 2019). Patients often have symptoms such as cough, hemoptysis, loss of appetite, dyspnea, and fatigue, which seriously affect the patient's physical health (Zhou et al., 2019). At present, the clinical treatment of non-small cell lung cancer is mostly surgical resection and lymph node dissection, the main goals are to improve the survival rate and prolong the survival time of patients.

In recent years, with the continuous development of thoracoscopy technology, thoracoscopy radical lung cancer surgery has gradually been applied to the treatment of nonsmall cell lung cancer (Venkitaraman et al., 2019; Inada et al., 2000). The thoracoscopic operation field is more clear, and has the advantages of minimally invasive, less bleeding, and rapid postoperative recovery. There is no need for thoracotomy, the operation time is shorter, and the cardiopulmonary function will not be damaged (Kawagoe et al., 2019). The results of this study show that the use of refined nursing in thoracoscopic surgery for lung cancer radical surgery can reduce the intraoperative blood loss of patients, shorten the length of hospital stay, and improve the patient's nursing satisfaction, which is worthy of clinical application.

Nutrition support care is also included in refined nursing care. Recently, studies have shown that appropriate management of nutrition can play an important role in supporting anti-tumor treatment. For example, synbiotic sheep milk ice cream can reduce the colon carcinogenesis in mouse (Balthazar et al., 2021) [33934866], and lactoferrin and linolenic acid can also inhibit the growth of colorectal tumor (Yao et al., 2021)[34131514]. A meta-analysis confirmed that the consumption of dairy products is associated with a reduced risk of colorectal cancer (Guo et al., 2021) [34122548]. In lung cancer, $\alpha$-lactalbumin can also significantly reduce the growth of lung cancer cells by inducing cell apoptosis (Li et al., 2019)[31447140].

However, there are some deficiencies in this study. First of all, the small sample size included in this study may affect the stability and popularization of the research results to a certain

Table 1. Comparison of intraoperative blood loss, extubation time, and hospital stay between the two groups of patients.

\begin{tabular}{|c|c|c|c|c|}
\hline variables & Experimental group $(n=65)$ & Control group $(n=65)$ & $t$ & $p$ \\
\hline Intraoperative blood loss $(\mathrm{mL})$ & $192.94 \pm 3.63$ & $221.46 \pm 4.31$ & -40.767 & $<0.01$ \\
\hline Extubation time (d) & $3.72 \pm 0.48$ & $3.90 \pm 0.67$ & -1.806 & 0.074 \\
\hline Hospital stay (d) & $10.08 \pm 1.64$ & $16.62 \pm 1.83$ & -21.441 & $<0.01$ \\
\hline
\end{tabular}

Table 2. Comparison of the incidence of complications between the two groups of patients.

\begin{tabular}{lccccccc}
\hline \multicolumn{1}{c}{ Group } & $n$ & Pleural effusion & $\begin{array}{c}\text { Incision } \\
\text { infection }\end{array}$ & Anastomotic bleeding & $\begin{array}{c}\text { Complications incidence } \\
(\%)\end{array}$ & $\chi^{2}$ \\
\hline Experimental group & 65 & 1 & 2 & 1 & 6.15 & 4.561 \\
Control group & 65 & 2 & 6 & 4 & 18.46 & 0.033 \\
\hline
\end{tabular}

Table 3. Comparison of overall nursing satisfaction between the experimental group and the control group.

\begin{tabular}{lcccc}
\hline \multicolumn{1}{c}{ Group } & Very satisfied & Generally satisfied & Dissatisfied & Total nursing satisfaction rate (\%) \\
\hline Experimental group & 49 & 12 & 4 & 93.85 \\
Control group & 36 & 17 & 12 & 81.54 \\
\hline
\end{tabular}


extent. Secondly, this study only analyzes the short-term effects of intensive care. The next step needs to study the long-term effects.

In conclusion, the clinical effect of fine nursing intervention in the nursing room of patients undergoing thoracoscopic lung cancer radical surgery is worthy of recognition. It can improve the clinical effect of patients, shorten the length of hospital stay, and improve the satisfaction of patients.

\section{Ethical approval}

All procedures performed in studies involving human participants were in accordance with the ethical standards of the institutional and/or national research committee and with the 1964 Helsinki declaration and its later amendments or comparable ethical standards. This study is approved by the Ethics Committee of People's Hospital of Deyang City. Written informed consent was obtained.

\section{Availability of data and material}

The datasets used or analysed during the current study are available from the corresponding author on reasonable request.

\section{Author contributions}

Caihong $\mathrm{HU}$ was the guarantor of integrity of the entire study and contributed to manuscript preparation and editing; Changming ZHAO carried out clinical studies and data analysis; Ping LAI contributed to definition of intellectual content; Xiaofang WANG carried out experimental studies and data acquisition; Zhengbo LIANG carried out study concepts and design, contributed to literature research, statistical analysis and manuscript review.

\section{References}

Alghamdi, H. I., Alshehri, A. F., \& Farhat, G. N. (2018). An overview of mortality \& predictors of small-cell and non-small cell lung cancer among Saudi patients. Journal of Epidemiology and Global Health, 7(Suppl. 1), S1-S6.

Bacha, S., Sghaier, A., Habibech, S., Cheikhrouhou, S., Racil, H., Chaouch, N., Zaouri, B., \& Chabbou, A. (2017). Combined C-reactive protein and Neutrophil to Lymphocyte ratio use predict survival innon-small-cell lung cancer. La Tunisie Medicale, 95(12), 229-235. PMid:29878284.

Balthazar, C. F., Moura, N. A., Romualdo, G. R., Rocha, R. S., Pimentel, T. C., Esmerino, E. A., Freitas, M. Q., Santillo, A., Silva, M. C., Barbisan, L. F., Cruz, A. G., \& Albenzio, M. (2021). Synbiotic sheep milk ice cream reduces chemically induced mouse colon carcinogenesis. Journal of Dairy Science, 104(7), 7406-7414. http:// dx.doi.org/10.3168/jds.2020-19979. PMid:33934866.

Bertaglia, V., Vallone, S., Pacchiana, M. V., \& Novello, S. (2017). Advanced squamous lung cancer: therapeutic options, future directions, unmet needs and results of a monocentric survey. Lung Cancer Management, 6(3), 93-107. http://dx.doi.org/10.2217/lmt2017-0011. PMid:30643575.

Calado, T., Antunes, M., Cabral, D., Alvoeiro, M., \& Felix, F. (2017). Surgical treatment for elderly patients with lung cancer. Revista Portuguesa de Cirurgia Cardio-Toracica e Vascular, 24(3-4),144.
Chen, B., Xia, W., Wang, Z., Zhao, H., Li, X., Liu, L., Liu, Y., Hu, J., Fu, X., Li, Y., Xu, Y., Liu, D., Yang, H., Xu, L., \& Jiang, F. (2019). Risk analyses of $\mathrm{N} 2$ lymph-node metastases in patients with T1 nonsmall cell lung cancer: a multi-center real-world observational study in China. Journal of Cancer Research and Clinical Oncology, 145(11), 2771-2777. http://dx.doi.org/10.1007/s00432-019-03006-x. PMid:31428933.

Chin, C. G., Yeh, J. S., Lin, Y. K., \& Tam, W. C. (2017). Superior vena cava syndrome complicated with acute pulmonary thromboembolism in a patient with lung cancer. Journal of Cardiology Cases, 17(1), 9-11. http://dx.doi.org/10.1016/j.jccase.2017.08.004. PMid:30279843.

Clarke, E., Curtis, J., \& Brada, M. (2019). Incidence and evolution of imaging changes on cone-beam CT during and after radical radiotherapy for non-small cell lung cancer. Journal of the European Society for Therapeutic Radiology and Oncology, 132, 121-126. http:// dx.doi.org/10.1016/j.radonc.2018.12.009. PMid:30825960.

Deng, S., Clowers, M. J., Velasco, W. V., Ramos-Castaneda, M., \& Moghaddam, S. J. (2020). Understanding the complexity of the tumor microenvironment in K-ras mutant lung cancer: finding an alternative path to prevention and treatment. Frontiers in Oncology, 9, 1556. http://dx.doi.org/10.3389/fonc.2019.01556. PMid:32039025.

Feng, C., Wu, J., Li, J., Deng, H. Y., Liu, J., \& Zhao, S. (2020). Advance directives of lung cancer patients and caregivers in China: a cross sectional survey. Thoracic Cancer, 11(2), 253-263. http://dx.doi. org/10.1111/1759-7714.13237. PMid:31851775.

Filippou, D., Kleontas, A., Tentzeris, V., Emmanouilides, C., Tryfon, S., Baka, S., Filippou, I., \& Papagiannopoulos, K. (2019). Extended resections for the treatment of patients with T4 stage IIIA nonsmall cell lung cancer (NSCLC) (T4N0-1M0) with or without cardiopulmonary bypass: a 15-year two-center experience. Journal of Thoracic Disease, 11(12), 5489-5501. http://dx.doi.org/10.21037/ jtd.2019.11.33. PMid:32030268.

Glatzer, M., Schmid, S., Radovic, M., Fruh, M., \& Putora, P. M. (2017). The role of radiation therapy in the management of small cell lung cancer. Breathe, 13(4), e87-e94. http://dx.doi.org/10.1183/20734735.009617. PMid:29928456.

Guo, L. L., Li, Y. T., Yao, J., Wang, L. S., Chen, W. W., He, K. Y., Xiao, L., \& Tang, S. H. (2021). Dairy consumption and risk of conventional and serrated precursors of colorectal cancer: a systematic review and meta-analysis of observational studies. Journal of Oncology, 2021, 9948814. http://dx.doi.org/10.1155/2021/9948814. PMid:34122548.

Hasan, S., White, R., Renz, P., Abel, S., Otaibi, Z., Monga, D., Colonias, A., \& Wegner, R. E. (2019). Optimal timing of thoracic radiotherapy in limited stage small cell lung cancer (SCLC) with daily fractionation: a brief report. Journal of the European Society for Therapeutic Radiology and Oncology, 132, 23-26. http://dx.doi.org/10.1016/j. radonc.2018.11.005. PMid:30825965.

Inada, K., Shirakusa, T., Yoshinaga, Y., Yoneda, S., Shiraishi, T., Okabayashi, K., Iwasaki, A., \& Kawahara, K. (2000). The role of video-assisted thoracic surgery for the treatment of lung cancer: lung lobectomy by thoracoscopy versus the standard thoracotomy approach. International Surgery, 85(1), 6-12. PMid:10817423.

Jiang, T., Zhou, C., Hu, J., \& Song, Y. (2019). Combination immune checkpoint inhibitors with platinum-based chemotherapy in advanced non-small cell lung cancer: what's known and what's next. Translational Lung Cancer Research, 8(Suppl. 4), S447-S450. http:// dx.doi.org/10.21037/tlcr.2019.11.10. PMid:32038935.

Kawagoe, I., Hayashida, M., Satoh, D., \& Inada, E. (2019). Intercostal misplacement of a thoracic epidural catheter discovered during lung cancer surgery: a case report. JA Clinical Reports, 5(1), 44. 
Kenamond, M. C., Siochi, R. A., \& Mattes, M. D. (2018). The dosimetric effects of limited elective nodal irradiation in volumetric modulated arc therapy treatment planning for locally advanced non-small cell lung cancer. Journal of Radiation Oncology, 7(1), 45-51. http://dx.doi. org/10.1007/s13566-017-0327-2. PMid:30220961.

Levy-Storms, L., Simmons, S. F., Gutierrez, V. F., Miller-Martinez, D., Hickey, K., \& Schnelle, J. F. (2005). A refined protocol for coding nursing home residents' comments during satisfaction interviews. The Journals of Gerontology. Series B, Psychological Sciences and Social Sciences, 60(6), S326-S330. http://dx.doi.org/10.1093/ geronb/60.6.S326. PMid:16260715.

Li, H. Y., Li, P., Yang, H. G., Wang, Y. Z., Huang, G. X., Wang, J. Q., \& Zheng, N. (2019). Investigation and comparison of the anti-tumor activities of lactoferrin, alpha-lactalbumin, and beta-lactoglobulin in A549, HT29, HepG2, and MDA231-LM2 tumor models. Journal of Dairy Science, 102(11), 9586-9597. http://dx.doi.org/10.3168/ jds.2019-16429. PMid:31447140.

Miao, J. L., Zhou, J. H., Cai, J. J., \& Liu, R. J. (2019). The association between fibroblast growth factor receptor 1 gene amplification and lung cancer: a meta-analysis. Archives of medical science. AMS, 16(1), 16-26. PMid:32051701.

Reymen, B. J. T., Van Gisbergen, M. W., Even, A. J. G., Zegers, C. M. L., Das, M., Vegt, E., Wildberger, J. E., Mottaghy, F. M., Yaromina, A., Dubois, L. J., Van Elmpt, W., Ruysscher, D., \& Lambin, P. (2020). Nitroglycerin as a radiosensitizer in non-small cell lung cancer: results of a prospective imaging-based phase II trial. Clinical and Translational Radiation Oncology, 21, 49-55.

Samson, P. P., Spraker, M. B., Badiyan, S. N., Vlacich, G., Robinson, C. G., \& Chaudhuri, A. A. (2019). Local consolidative therapy for oligometastatic non-small cell lung cancer. Journal of Thoracic Disease, 11(12), 5649-5651. http://dx.doi.org/10.21037/jtd.2019.11.19. PMid:32030290.

Shirai, S., Yamauchi, Y., Yokote, F., Sakai, T., Saito, Y., Sakao, Y., \& Kawamura, M. (2019). Dynamics of coagulation factor XIII activity after video-assisted thoracoscopic lobectomy for non-small cell lung cancer. Journal of Thoracic Disease, 11(12), 5382-5389. http://dx.doi. org/10.21037/jtd.2019.12.08. PMid:32030256.

Sun, H., Wang, H., Shi, L., Wang, M., Li, J., Shi, J., Ni, M., Hu, X., \& Chen, Y. (2020). Physician preferences for chemotherapy in the treatment of non-small cell lung cancer in China: evidence from multicentre discrete choice experiments. BMJ Open, 10(2), e032336. http://dx.doi.org/10.1136/bmjopen-2019-032336. PMid:32051302.

Tian, X., Ma, J., Wang, T., Tian, J., Zhang, Y., Mao, L., Xu, H., \& Wang, S. (2020). Corrigendum: long non-coding RNA HOXA transcript antisense RNA myeloid-specific 1-HOXA1 axis downregulates the immunosuppressive activity of myeloid-derived suppressor cells in lung cancer. Frontiers in Immunology, 10, 2929. http://dx.doi. org/10.3389/fimmu.2019.02929. PMid:32038606.

Venkitaraman, B., Lei, J., Liang, W., \& Jianqiao, C. (2019). Uniportal video-assisted thoracoscopy surgery in lung cancer: largest experience.
Asian Cardiovascular \& Thoracic Annals, 27(7), 559-564. http:// dx.doi.org/10.1177/0218492319868651. PMid:31407931.

Wang, J., Zhang, J., Xu, L., Zheng, Y., Ling, D., \& Yang, Z. (2017). Expression of HNF4G and its potential functions in lung cancer. Oncotarget, 9(26), 18018-18028. http://dx.doi.org/10.18632/ oncotarget.22933. PMid:29719587.

Wang, X., Liu, Z., Sui, X., Wu, Q., Wang, J., Xu, C. (2019). Elemene injection as adjunctive treatment to platinum-based chemotherapy in patients with stage III/IV non-small cell lung cancer: a meta-analysis following the PRISMA guidelines. Phytomedicine: International Journal of Phytotherapy and Phytopharmacology, 59, 152787.

Xie, L. J., Li, J. F., Liu, Z., Zhang, F., Zhao, C., Qin, L. P., Zhang, T. J., \& Cheng, M. H. (2017). Immunoglobulin G4-related lung disease presenting as lung cavitating mass and mimicking lung cancer. Archives of Rheumatology, 32(4), 365-369.

Xing, D. F., Xu, C. D., Liao, X. Y., Xing, T. Y., Cheng, S. P., Hu, M. G., \& Wang, J. X. (2019). Spatial association between outdoor air pollution and lung cancer incidence in China. BMC Public Health, 19(1), 1377. http://dx.doi.org/10.1186/s12889-019-7740-y. PMid:31655581.

Yao, Q., Li, H., Fan, L., Huang, S., Wang, J., \& Zheng, N. (2021). The combination of lactoferrin and linolenic acid inhibits colorectal tumor growth through activating AMPK/JNK-related apoptosis pathway. PeerJ, 9, e11072. http://dx.doi.org/10.7717/peerj.11072. PMid:34131514.

Yoo, J. K., Lee, J. M., Kang, S. H., Jeon, S. H., Kim, C. M., Oh, S. H., Kim, C. H., Kim, N. K., \& Kim, J. K. (2019). The novel microRNA hsa-miR-CHA1 regulates cell proliferation and apoptosis in human lung cancer by targeting XIAP. Lung Cancer, 132, 99-106. http:// dx.doi.org/10.1016/j.lungcan.2018.04.011. PMid:31097102.

Yu, M., Zhao, Q., Li, Y., Zhang, S., Xu, Y., Gong, Y., Zhu, J., Ding, Z., Wang, J., Peng, F., Wang, Y., Huang, M., Ren, L., Lu, Y., \& Liu, Y. (2018). Progression of central nervous system metastases in advanced nonsmall cell lung cancer patients effectively treated with first-generation epidermal growth factor receptor-tyrosine kinase inhibitor. Cancer Biotherapy \& Radiopharmaceuticals, 33(10), 421-426. http://dx.doi.org/10.1089/cbr.2018.2493. PMid:31050549.

Zhang, N., Hu, H., Fu, Y., He, F., Wang, L., Zhuang, S., \& Ding, M. (2018). The overexpression of PDGF-BB and its receptor is correlated with lymphatic metastasis in patients with non-small cell lung cancer. International Journal of Clinical and Experimental Pathology, 11(12), 6010-6017. PMid:31949689.

Zhou, M., Chen, X., Zhang, H., Xia, L., Tong, X., Zou, L., Hao, R., Pan, J., Zhao, X., Chen, D., Song, Y., Qi, Y., Tang, L., Liu, Z., Gao, R., Shi, Y., \& Yang, Z. (2019). China National Medical Products Administration approval summary: anlotinib for the treatment of advanced non-small cell lung cancer after two lines of chemotherapy. Cancer Communications, 39(1), 36. http://dx.doi.org/10.1186/ s40880-019-0383-7. PMid:31221221. 